\title{
Revista \\ Brasileira \\ de Enfermagem \\ REBEn \\ A produção científica sobre Administração em
Enfermagem no Brasil no período de 1947 a 1972
}

HISTÓRIA DA ENFERMAGEM

The Nursing Administration scientific publications in Brasil since 1947 until 1972

La produción científica sobre la Administración en Enfermería en Brasil en el periodo de 1947 a 1972

Elaine Guimarães Martins

Graduanda Curso de Graduação em Enfermagem - FACENF - UNISA

(Universidade de Santo Amaro Membro do Centro de Pesquisas sobre História da Enfermagem da UNISA elaine.gm@superig.com.br

Maria Cristina Sanna

Enfermeira. Doutora em Enfermagem. Professora Titular da FACENF-UNISA. Líder do Centro de Estudos e Pesquisas sobre História da Enfermagem da UNISA

Trabalho de Conclusão de Curso de Graduação em Enfermagem apresentado como exigência para a obtenção do título de Bacharel em Enfermagem pela FACENF - UNISA Vinculado à linha de Pesquisa História da Administração em Enfermagem.

\section{RESUMO}

AAdministração em Enfermagem foi adicionada ao currículo assim que este preparo tornou-se uma necessidade evidente. Descrever a trajetória histórica das produções científicas sobre a disciplina, destacando marcos deste caminhar para compreender como foram produzidos e incorporados esses conhecimentos, são os objetivos do presente trabalho. O estudo abrangeu o período de 1947 a 1972, capturando-se, na base eletrônica de periódicos de enfermagem - PERIENF, 19 indicações que, submetidas à análise temática, revelaram que, desde os anos 40, as enfermeiras declaravam dificuldades de desempenho administrativo, evoluíram para a inclusão deste conteúdo nos cursos e exemplificaram como este foi sendo organizado até que, pela definição do Currículo Mínimo do Curso de Enfermagem e Obstetrícia em 1972, ficou assegurado o espaço dessa disciplina. Descritores: Administração hospitalar; História da enfermagem; Currículo/educação.

\section{ABSTRACT}

The Nursing Administration was added to the Nursing Undergraduation Currículum when the evidence of this need came clear to the brazilian nurses. The main objective of the present investigation is to describe the history pathway of scientific productions about Nursing Administration to evidence the special points of this history, intended to contribute to the understanding of the sequence of their productions and the utilization of this concepts in the administration nursing practice. The study referred from 1947 to 1972, by the searching in the electronic nursing scientific publications data base named - PERIENF. The results were 19 indications submitted to a thematic analysis treatment. This procedure reveals that since the forties the nurses were conscious of the difficulties they had experimented in their administration performance, growing up to the inclusion of this theme in the undergraduate courses and demonstrating its organization until the definition of the "Currículo Mínimo do Curso de Enfermagem e Obstetrícia" in 1972, granting a special place of this discipline.

Descriptors: Hospital administration; History of Nursing; Curriculum/education.

\section{RESUMEN}

LaAdministración en Enfermería fue adicionada al currículo aunque este preparo constiuiyó-se en una necessidad evidente. Describir la trajectória histórica de las produciones científicas sobre la disciplina, destacando-se los marcos deste caminar para compreender como fueram produzidos y incorporados tales conocimientos, son los objectivos del presente trabajo. El estudio abarcó el periodo de 1947 a 1972, obtenendo-se, en la basis electronica de periódicos de enfermería llamada - PERIENF, 19 indicaciones que, submetidas a analisis temática, reveló que desde los años 40 las enfermeras declaravam dificultad de desempeño administrativo, evoluyendo para la inclusión deste contenido en los cursos e exemplificaran como este fue organizando-se até que, por la ocasión de la definición de lo Currículo Mínimo de lo Curso de Enfermería y Obstetrícia, en 1972, se asseguró lo espacio de essa disciplina.

Descriptores: Administración hospitalaria; História de la enfermería; Curriculum/educación.

Martins EG, Sanna MC. A produção científica sobre Administração em Enfermagem no Brasil no período de 1947 a 1972. Rev Bras Enferm 2005 mar-abr; 58(2):235-9.

\section{INTRODUÇÃO}

A administração é um processo integrado, visando à obtenção de resultados específicos, o qual abrange coletivamente o grupo envolvido com o processo de administrar e controlar uma organização.

Também se definiu a administração como sendo todas as funções executadas de maneira racional, por uma pessoa ou grupo de pessoas a fim de alcançar determinados objetivos que foram formulados por eles próprios ou por outros ${ }^{(1)}$.

Numa mesma época se definia a administração em enfermagem como seleção, provisão e utilização de recursos para 0 alcance de uma finalidade, cujas realizações são desejáveis ou 
compulsórias, encaminhando-se a um processo individual e não como um simples manejo de objetos ${ }^{(2)}$.

Partindo deste pressuposto, as enfermeiras iniciaram uma jornada na busca contínua de informações e conhecimentos sobre essa nova ciência de administrar os benefícios que trariam à Enfermagem, visando à obtenção de uma boa administração, trazendo assim ganhos e benefícios para 0 grupo envolvido na assistência ao paciente.

É importante salientar que essas enfermeiras enfrentaram muitas barreiras para a busca dessa nova ciência de administrar, sendo introduzida relativamente há pouco tempo no seu preparo formal. Muitas não tinham total conhecimento de como fazê-lo, ao tempo em que tinham a convicção de que não estavam sendo eficientes no trabalho. Prova disse é o discurso de Menezes ${ }^{(3)}$.

Sendo assim, a Administração Aplicada à Enfermagem foi adicionada ao currículo das escolas assim que esta se tornou plenamente consciente de suas reais atribuições, com uma visão de preparar as futuras enfermeiras para a função de líder das atividades e seu desenvolvimento administrativo ${ }^{(4)}$.

Este trabalho vai sendo aperfeiçoado quanto mais estiver sendo executado, sendo que as metas administrativas estabelecidas visam, não somente a consecução dos objetivos formulados no período do século XX mas também a obtenção máxima do desenvolvimento profissional destas enfermeiras ao longo do tempo.

Seu estudo vem a partir de informações obtidas de problemas e dificuldades já vivenciados, que são associados com conceitos derivados de campos da ciência da Administração que são devidamente adaptados, ou seja, uma ciência que evolui a cada nova descoberta e experiência, como qualquer ciência aplicada.

A produção científica sobre Administração em Enfermagem vem se desenvolvendo de modo eficiente e visa preparar melhor as enfermeiras para as funções de liderança das atividades administrativas, interrelacionando o desempenho de seu trabalho juntamente com a cultura organizacional, e outros conhecimentos científicos, procurando, assim, ter uma melhor dinâmica ao administrar, e que também seja eficiente para uma boa obtenção de resultados.

A Enfermagem, em sua trajetória histórica, enfrentou grandes desafios. Muitas vezes as condições de trabalho eram desfavoráveis, pois as enfermeiras não tinham total aptidão para o desenvolvimento de administrar e gerenciar, pois eram recém-formadas e entravam no mercado de trabalho sem nenhuma experiência de como fazê-lo e de como lidar com as dificuldades a serem enfrentadas, mas já eram designadas para funções de mando cada vez mais complexas.

Hoje, o preparo do enfermeiro para a administração é diferente dos primórdios da formação desse profissional no país, mas as transformações que ocorreram nesse período não são perceptíveis para quem não as acompanhou. Assim, parece oportuno resgatar a história das produções científicas sobre Administração em Enfermagem, destacando os grandes marcos históricos que, sem dúvida, impulsionaram sua estrutura, ambiente e tecnologia, aperfeiçoando o seu trabalho e levando a um melhor desenvolvimento profissional.

\section{OBJETIVO}

Descrever a trajetória histórica da produção científica sobre Administração em Enfermagem brasileira, destacando os grandes marcos deste caminhar para compreender como foram produzidos e incorporados esses procedimentos até que a disciplina se constituísse como parte integrante do conteúdo do curso, com identidade própria.

\section{METODOLOGIA}

Trata-se de um estudo descritivo, de caráter histórico-social quantitativo e bibliográfico, que tem por finalidade, resgatar aspectos inerentes às produções científicas sobre Administração em Enfermagem de 1947, quando começou a grande trajetória das publicações na ciência de administrar em enfermagem a 1972, quando houve a promulgação do currículo mínimo que somou a Enfermagem à Obstetrícia.

A população estudada foram as publicações científicas que estão disponibilizadas na base de dados PERIENF, que surgiu juntamente com a Escola de Enfermagem da Universidade de São Paulo em 1942. Hoje, a PERIENF é um dos recursos oferecidos pelo Serviço de Biblioteca e Documentação da EEUSP, que tem como objetivo divulgar, aos pesquisadores e profissionais, a produção brasileira de Enfermagem. É atualizada periodicamente e tem cerca de oito mil referências bibliográficas, grande parte delas acompanhada de resumos.

A escolha dessa fonte de dados se deu devido ao fato das bases eletrônicas, como o LILACS (Literatura Latino Americana de Ciências da Saúde), por exemplo, ter-se iniciado apenas nos anos 80 do século XX, 0 mesmo aplicando-se à BDENF (Bibliografia Brasileira de Enfermagem), 0 que não se coadunava com o recorte temporal definido para o presente trabalho. Também as bases eletrônicas internacionais, por sua vez, não dariam conta do objeto de estudo no contexto em que foi desenhado - a Enfermagem Brasileira. Assim, tomou-se como referência exclusiva a base citada.

A coleta de dados, então, foi realizada através de banco de dados disponibilizado eletronicamente, na base de dados PERIENF, utilizando-se as palavras-chave: "Administração" e "Enfermagem", quando foram relacionados os anos de 1942 a 1972, de interesse para o estudo. Foram encontrados, apenas a partir de 1947, 46 artigos e duas teses, todos em português, e foram selecionados destes, após a leitura dos resumos e/ou dos textos na íntegra, 19 artigos, estes de grande interesse para 0 assunto a ser estudado. Os outros 29 artigos foram excluídos pois não eram relacionados diretamente com o objeto do presente estudo e, também, por serem editoriais e relatórios de prestações de contas daAssociação Brasileira de Enfermagem ( $A B E n$ ) e congêneres.

As duas teses citadas não foram selecionadas pois não estavam disponíveis, na integra, para se obter e fazer cópia deste material. Uma delas, consultada posteriormente, em cópia não autenticada de biblioteca particular, abordava o tema de forma genérica, mais voltada para os aspectos de expansão do papel profissional e as inadequações curriculares do ponto de vista de sua vinculação ao modelo americano, e não propriamente se referia à disciplina de Administração. Quando o fez, ainda usou uma fonte mais antiga, integrada aos artigos incluídos no presente estudo, optandose por preferir a fonte primária.

Os 19 artigos selecionados foram copiados e submetidos a procedimento de leitura, resumo da obra e fichamento, para melhor análise. Os artigos analisados foram agrupados por similaridade e pertinência a partir dos quais se criou as categorias: "Estratégia de funcionamento da estrutura organizacional"; "Análise e considerações sobre o preparo de recursos humanos na Enfermagem"; e "Ensino e pesquisa sobre Administração Aplicada a Enfermagem", destacando-se os grandes marcos históricos da evolução das produções científicas sobre Administração em Enfermagem no período estudado.

\section{RESULTADOS E DISCUSSÃO}

As categorias apresentadas indicam o que as enfermeiras vêm declarando as suas dificuldades e preocupações, e também falando-nos das suas vitórias e conquistas na Administração Aplicada à Enfermagem.

Em um período da história, nas produções científicas, as enfermeiras reconheceram que tinham o dever de estarem inteiradas dos conhecimentos e das movimentações políticas, das relações humanas e da competência técnica, partindo assim dos fatores da administração que são: planejamento, organização de recursos para a execução do plano, execução e avaliação da administração, como Paul(2) disse.

Inicialmente os artigos em inglês, de interesse para a classe, eram traduzidos para o português. As produções científicas de enfermagem brasileiras nos anos 40 do século XX eram muito escassas devido a 
poucos enfermeiros escreverem artigos. Com o passar dos anos, os enfermeiros começaram a escrever artigos científicos e, com isso, aumentaram a quantidade de publicações que inicialmente eram feitas na revista Anais de Enfermagem, mais tarde denominada Revista Brasileira de Enfermagem. Este periódico foi, portanto, aquele em que se encontrou a maior parte das publicações analisadas e não poderia ser diferente, já que as revistas Gaúcha de Enfermagem, da Escola de Enfermagem da USP e Bahiana de Enfermagem, foram criadas em data posterior à anteriormente citada e eram as únicas que existiam até $1972^{(5)}$.

\subsection{Estratégia de funcionamento da estrutura organizacional}

As enfermeiras, tendo em vista a sua sensibilidade e percepção, deramse conta da importância da administração, e com isso, começaram ${ }^{(6)}$ uma busca constante dos princípios do ensino da Administração. A Enfermagem, portanto, fez um momento de aproximação dos conceitos e princípios da Administração com o propósito de investigar essas novas idéias para preparar soluções para as dificuldades a serem enfrentadas na administração da assistência de enfermagem.

Um dos marcos históricos iniciais dessa busca do conhecimento sobre administração se deu a partir da implantação de um sistema de anotações e relatórios diários, os quais permitiam um controle dos planos de atividades já pré-estabelecidos, além de trazer as informações e selecionar os motivos que determinaram as ocorrências e a necessidade de registrá-las.

Tendo essa nova idéia e consciência da importância da administração, a enfermeira deixou de olhar para si mesma apenas como mais uma funcionária da instituição e percebeu que era capaz de pensar, ser criativa, e de ter iniciativas, podendo ter vários níveis de responsabilidades e de dar uma ótima contribuição para a tomada de decisão. Uma condição necessária foi a centralização da informação a seu favor, pois, tendo as informações adequadas e antecipadas, poderia antecipar-se e preparar as ações estratégicas a serem aplicadas.

Para isso determinavam que se deveria fazer um planejamento adequado, tangível, inteligente e seguro para a organização do serviço de enfermagem, e que também pudesse ser de fácil compreensão, de padrões aceitáveis, para que se pudesse prever também problemas e resolvê-los de antemão.

Há múltiplas facetas e ângulos que se apresentaram. Isto implicou muito trabalho, esforço, estudo, pesquisa e, acima de tudo, uma vasta experiência, o que muitas vezes não acontecia porque as enfermeiras eram pouco numerosas ${ }^{(5)}$ e recém-graduadas, espalhavam-se pelo território nacional nas funções parciais dos seguintes locais em ordem de importância: Assistência Hospitalar, Saúde Pública e Ensino de Enfermagem.

As enfermeiras faziam seus planejamentos para a organização do serviço de enfermagem mas a produtividade era insuficiente e ineficaz porque, além de inexperiente havia falta de preparo específico nessa área. Muitas vezes, enfermeiras recém-formadas, que acabaram de receber seus diplomas, eram convidadas a ocuparem cargos de grande importância para a Enfermagem e para o Sistema de Saúde, como se nota no texto a seguir:

Nós, as enfermeiras chefes, temos consciência de que não estamos sendo inteiramente eficientes em nosso trabalho [...]. Mal recebemos o diploma de enfermeira, aparecem as propostas e nos lançamos aos cargos de chefia, antes que eles sejam preenchidos por pessoas que, embora bem intencionadas, nem o diploma de enfermagem possuem ${ }^{(5)}$.

A essas enfermeiras recém-formadas, o ensino ministrado não lhes conferiu total aptidão para os desafios da administração, e também não tiveram tempo de sedimentar suas experiências.

Apesar de algumas falhas, ainda assim, as enfermeiras conseguiram desempenhar adequadamente 0 seu papel na função de administrar tanto que, a partir da década de 50 do século $X X$, passaram a enfrentar 0 administrador hospitalar, demonstrando sua competência perante o mesmo, mantendo uma relação de simetria entre 0 administrador e a enfermeira, para o forte crescimento das obrigações, garantindo bom desenvolvimento da competência técnica e social, e estimulando a confiança depositada nas enfermeiras.

Com o avanço da Administração em Enfermagem, com base em modelos americanos, se criou o cargo de supervisora que, inicialmente, não era muito bem definido para a Enfermagem Brasileira:

... Ao ser delegada essa função [supervisão], aquêle que a recebe e executa é designado "supervisor", o que faz com que alguns a considerem uma função à parte, perdendo de vista o sentido da supervisão dentro do plano geral da Administração(7).

Depois de uma longa discussão, chegaram a um consenso de que a supervisão em enfermagem é uma função dentro dos planos da administração $0^{(7)}$. Definiu-se, assim, que a supervisão é a alma da produtividade e da eficiência das organizações; que visa a melhor prestação de serviço no cuidar, a promoção, o estímulo e o patrocínio do progresso e do bem estar, além da capacidade de agir, reagir e liderar para conseguir melhores resultados na instituição(7). Para tanto é oportuno dizer que a supervisão tinha, naquela época, como objetivos, o aperfeiçoamento do trabalho que está sendo executado, estabelecendo relações de dominação entre supervisor e supervisionado para que ambos conseguissem bons resultados, de modo que alcançassem adequadamente 0 objetivo proposto pela Instituição.

Para que os objetivos da supervisão em enfermagem fossem alcançados com exatidão, era preciso ter uma harmonia em questões a serem interpretadas como responsabilidade nas decisões administrativas e ser também mediador entre a administração e 0 trabalhador. Assim, obteve-se a eficácia entre dois pontos, o do trabalhador e 0 administrador, aplicando-se uma avaliação que permitisse a flexibilidade, mudança, alterações ou adequações do planejamento da supervisão.

Para obtê-lo a supervisora de enfermagem devia ter uma vasta experiência no campo administrativo, o que lhe daria o conhecimento e, tendo o bom senso nas tomadas de decisões, para resolver problemas da melhor forma possível e adequada, alcançaria as metas planejadas. Teixeira ${ }^{(7)}$ cita, entre as qualidades pessoais de um líder para o exercício da função de supervisão, a empatia, 0 autocontrole e o equilíbrio emocional, mas afirma: "Além dessas qualidades, faz-se porém necessário um preparo técnico específico e experiência abundante no campo em que vai exercer a supervisão".

Com a evolução da Administração aplicada à Enfermagem surgiu outra função, a de auditoria, sendo que esta não exigia vasta experiência e conhecimento especializado, mas sim um grande incentivo e liderança para criar condições para a implantação de um sistema de avaliação contínua, para traduzir as ações de enfermagem. Ribeiro ${ }^{(8)}$ alertou que: "os objetivos deveriam ser estabelecidos de forma clara e precisa e passíveis de mensuração, isto é, que permitam a aplicação de um método de avaliação ou de pesquisa, para traduzir as ações de enfermagem em dados estatísticos".

Dessa maneira, a auditoria provocou a descentralização dos serviços de enfermagem, o que trouxe um grande beneficio, pois the competiu tanto planejar quanto implementar, coordenar e controlar com mais eficácia o espaço de trabalho que Ihe competia. Com isso, obteve-se ótimos resultados do Serviço de Enfermagem, atestados pelos relatórios contínuos de qualidade. Através dos mesmos podiase retirar dados estatísticos que avaliavam as ações de enfermagem.

Outro ponto que não se deve esquecer é que a auditoria em enfermagem não podia permanecer como um processo ignorado, pois, através dela, poder-se-ia traçar novos horizontes, aumentando assim a qualidade das ações de enfermagem, que não se mediam nem em 
tempo ou gastos, mas somente numa busca constante pela ótima qualidade do serviço de enfermagem como um todo.

4.2 Análise e considerações sobre o preparo de recursos humanos na Enfermagem

A Enfermagem começou como responsabilidade familiar, logo convertida em responsabilidade tribal. Surgiu do passado como uma ocupação inicialmente sem treinamento, logo, com certo adestramento e, finalmente, ensinada como uma arte para o cuidado do paciente ${ }^{(9)}$.

Com esse pensamento, a Enfermagem veio se expandindo para atender, cada vez mais, às suas necessidades no serviço de saúde, de uma forma muito eficaz.

A Enfermagem é a "proteção" ao indivíduo vulnerável. É uma relação humana entre o indivíduo que está doente ou necessita de um serviço de saúde e um grupo de enfermagem ${ }^{(9)}$.

Com o aumento da demanda de indivíduos precisando do grupo de enfermagem, percebeu-se que o mesmo se deparava com um grande problema a ser enfrentado: "a falta de funcionários, comprometendo a qualidade do cuidado prestado ao paciente"(9).

Para sanar esta dificuldade, incentivou-se o recrutamento de candidatas através das escolas de enfermagem para funções de enfermeiras e de auxiliares de enfermagem, como também se selecionou atendentes de enfermagem pelo Serviço Especial de Saúde Pública (SESP) ${ }^{(10)}$.

$O$ recrutamento era feito da seguinte forma: as enfermeiras e auxiliares de enfermagem eram encaminhadas com cartas de recomendações das escolas de enfermagem e, em se tratando das atendentes de enfermagem, este recrutamento podia ser feito através de anúncios públicos ${ }^{(11)}$. Alcântara ${ }^{(1)}$ explicou: "Tratando-se porém, de atendentes, êstes podem ser recrutados através de anúncios de jornais ou comumente, são recrutados por pessoas que trabalham no hospital, ao terem conhecimento de vagas existentes".

Nessas condições, as enfermeiras eram também capazes de recomendar um quadro adequado de pessoal apto a compreender os requisitos da profissão, empenhando-se na criação de padrões, segundo os quais, não só pudessem trabalhar eficientemente, como formar bons profissionais $^{(11)}$.

Para fazer a seleção das candidatas era recomendável que a profissional responsável fosse uma enfermeira conhecedora de técnicas de entrevista, uma vez que esta era considerada uma boa técnica de seleção.

Logo após a seleção, eram feitos treinamentos intensivos diferentes entre enfermeiras, auxiliares e atendentes, sendo estes todos supervisionados por uma enfermeira. Com isto, cada um destes tomou 0 seu pleno conhecimento das funções que lhes competiam.

Partindo desse pressuposto, estabeleceram regras básicas para a execução da importante tarefa de administrar. "Não existe maior responsabilidade do que a de selecionar enfermeiras adequadas para 0 complexo de regras que se desenvolve tão rapidamente neste mundo da enfermagem"(11).

Florence Nightingale afirmou que as "profissões, como as nações, só podem florescer se houver um senso individual de responsabilidade de classe". Assim, formando enfermeiras na época estudada, as professoras obrigavam-se a estimular essa "consciência de classe", não só dentro da profissão, mas por todo lugar onde a saúde estava sendo protegida pela Enfermagem profissional(11), com maior ênfase a partir dos anos 60 .

Com este pensamento, não somente se supriu a necessidade de um grupo maior na Enfermagem, mas também aumentou a eficiência do serviço de enfermagem. Para isso, as enfermeiras encaminhavam os seus funcionários a uma constante reciclagem e aprimoramento dos seus conhecimentos, para ter sempre um bom funcionário, qualificados, para um melhor desenvolvimento das práticas de enfermagem.

Esse processo operacional respondia às demandas presentes, de acordo com as necessidades prioritárias de saúde, com a compreensão, estímulo e recursos necessários para fazer com que a Enfermagem fosse um instrumento efetivo e de qualidade, tendo em vista um corpo altamente qualificado e responsável nos diversos setores, tanto operacional, quanto administrativo.

É importante dizer que, ao passar por esse processo de reciclagem e aprimoramento, promoveu-se uma avaliação que permitia dinamizar 0 trabalho e os contínuos progressos destes participantes, pois, a partir destas avaliações, poder-se-ia fazer mudanças na organização do trabalho, tendo um conhecimento suficiente e adequado para tanto, o que fazia com que este funcionário viesse a mudar a imagem que tinha de si próprio. Nas palavras de Viegas( ${ }^{(6)}$ :

"Não importa a perfeição com que as enfermarias sejam organizadas e aparelhadas, não importa a exatidão com que sejam planejados os cuidados de enfermagem a se dispensar aos enfermos, se a enfermeirachefe falha na direção do pessoal sob suas ordens. Se não consegue interessá-lo, não poderá contar com a sua cooperação e toda economia do trabalho sofrerá".

Assim, a preocupação com o quantitativo e a qualidade dos recursos humanos passa a ser prioridade para a administração no ambiente hospitalar.

\subsection{Ensino de Administração em Enfermagem}

Acompanhando a evolução e as tendências da educação moderna e, principalmente, a aplicação desta à Enfermagem brasileira, os objetivos propostos para o programa de Administração Aplicada à Enfermagem evidenciavam a preocupação em preparar futuros líderes para a profissão(4).

É oportuno dizer que para a reforma curricular acontecer, houve muitas falhas das enfermeiras recém-formadas pois, mal deixavam os bancos escolares, assumiam cargos de grande responsabilidade, ou iriam para supervisão em saúde pública e, na maior parte das vezes, iriam para escolas ensinar estudantes, sem o preparo adequado. Com isso questiona-se: será que estas enfermeiras estavam preparadas adequadamente? Eis a questão a ser respondida.

Essas enfermeiras seguiam modelos internacionais e esse preparo era básico e indispensável para a formação, mas também esses mesmos modelos eram adaptações para a realidade do Brasil, nem sempre com muito sucesso. Schott ${ }^{(12)}$ indagou:

"Nos países onde o "industrialismo" e o "socialismo" estão bem estabelecidos e onde os governos não têm espirito profissional, a tarefa é grande, pois como poderão ser oferecidos a uma enfermeira em potencial, os previlégios de membros de uma organização profissional, quando existe pouco ou nenhum apoio, ao nível profissional por parte dos administradores?"

Devido às dificuldades que muitas enfermeiras vinham enfrentando, começou a se questionar sobre os modelos internacionais que elas seguiam. Então, começou a se rever as diretrizes curriculares e a despir o currículo do que havia de supérfluo, com a finalidade de reservar uma carga horária para as teorias e a prática da Administração Aplicada à Enfermagem. Esta medida teve como objetivo preparar pessoas que, além de adquirirem o preparo para o cuidar, fossem também capazes de administrar serviços, de ensinar e de fazer supervisão de pessoal.

Com essa sensibilidade e perspectiva, as enfermeiras, ou grande parte destas, que estavam exercendo funções de administração, supervisão e ensino, puderam enfrentar, com mais destreza, as dificuldades administrativas.

Essa medida de ensino de Enfermagem veio proporcionar, ao estudante, os conhecimentos dos princípios da Administração e fazer a relação destes com a Enfermagem, tendo-se a plena consciência das reais atribuições e responsabilidades da Enfermagem com a organização.

Também foi elaborado um programa de estágio de Administração Aplicada à Enfermagem, cujo objetivo era oferecer ao estudante, oportunidades de conhecer a organização e o funcionamento do hospital, e 
também para desenvolver o senso de responsabilidade quanto ao planejamento, orientação, execução e avaliação de um plano de supervisão.

Embora o ensino de Administração para a Graduação em Enfermagem já fosse mencionado, sem muita ênfase, no Decreto No. 27426/49 de 14 de novembro de 1949, que aprovava o Regulamento Básico para os Cursos de Enfermagem e de Auxiliar de Enfermagem no Brasil, baseado no "Programa Educativo da Escola de Enfermagem", proposto pelo International Council of Nursing ${ }^{(13)}$, a Escola de Enfermagem Anna Nery já oferecia essa formação, mesmo que nunca tivesse criado uma disciplina específica para tanto.

Como indica Sanna ${ }^{(14)}$, houve uma revisão do currículo daquela escola em 1943, no entanto, o conteúdo continuou diluído na disciplina de Ética de Enfermagem

Na Escola de Enfermagem de Ribeirão Preto, Alcântara( ${ }^{(15)}$ adotou a mesma estratégia, só que distribuindo o conteúdo entre Saúde Pública e Psicologia Educacional e Didática.

Já na Escola de Enfermagem da Universidade de São Paulo, que iniciou suas atividades em 1942, a introdução desses conceitos foi mais incisiva. De fato, em 1952, Pinheiro(13) já defendia essa posição e as pioneiras na introdução do conteúdo de Administração em Enfermagem com identidade própria no currículo, Ribeiro, Martinez e Carvalho ${ }^{(8)}$, explicaram o porquê:

"O ensino dos princípios de Administração e sua aplicação na Enfermagem foram introduzidos no currículo de nossa escola assim que se tomou consciência das reais atribuições da enfermeira em nosso meio [...] essa disciplina visa preparar a enfermeira para as funções de liderança, não a afasta, contudo, do cuidado à cabeceira do paciente, sua função precípua, pelo contrário, dá a ela meios para proporcionar estes cuidados com mais eficiência".

Para isso tinha o acompanhamento da enfermeira-chefe e, gradualmente, a aluna ia se tornando responsável pela administração da enfermaria, unidade de trabalho.

Seguindo esse programa proposto de Administração Aplicada à Enfermagem evidenciou-se que havia uma preocupação em preparar futuros lideres da profissão, dando-se oportunidades para se habituar às rotinas de uma instituição e meios para assumir a responsabilidade de liderança da equipe de enfermagem.

\section{REFERÊNCIAS}

1. Alcântara G. Organização de Pessoal. Rev Bras Enferm 1957;10(4):363-68.

2. Paul E. Princípios de administração aplicados ao serviço de Enfermagem. Rev Bras Enferm 1958;11(3):202-16.

3. Menezes AL. Problemas que afetam uma boa administração do serviço de Enfermagem hospitalar. Rev Bras Enferm 1961;14(5):47884.

4. Ribeiro CM. Auditoria de serviço de Enfermagem. Rev Bras Enferm 1972;25(4):91-103.

5. Carvalho ZA. O Valor da Formação da enfermeira chefe. 1. o paciente; 2. as alunas de enfermagem; 3 . administração da enfermaria. Anais de Enfermagem 1947;16(2): 28-31.

6. Viegas C. Eficiente orientação do pessoal. Anais de Enfermagem 1948;1(1):110-12.

7. Teixeira MS. Supervisão. Rev Bras Enferm 1963;16(6): 446-53.

8. Ribeiro CM, Martinez BM, Carvalho AC. Programação de administração aplicada à Enfermagem para o curso de graduação em Enfermagem. Rev Bras Enferm 1965;18(1):7-37.
As alterações curriculares determinadas pela legislação de Ensino e/ou pela disputa entre as escolas citadas pela hegemonia do modelo formador, se prolongaram por muito tempo. Porém, com a promulgação da Resolução n. 4/72 do Conselho Federal de Educação, que definiu o Currículo Mínimo dos Cursos de Enfermagem e Obstetrícia, a disciplina, com a denominação "Administração Aplicada à Enfermagem" finalmente foi reconhecida como detentora de identidade própria.

\section{CONCLUSÃO}

Este estudo veio ao encontro do presente com o passado, pois a Enfermagem está "envolvida em uma relação de tríplice aliança: a relação da Enfermagem com a organização, os assuntos pertinentes à profissão e 0 ensino de enfermagem ${ }^{(9)}$ ".

Assim, a Enfermagem procurou aproximar-se da ciência da Administração, pois percebeu ${ }^{(12)}$ a importância dos princípios daquela ciência aplicando-os à Enfermagem. Nota-se a existência dessas enfermeiras pioneiras que tiveram a sensibilidade e a percepção de adequar a Administração à Enfermagem.

Com o passar do tempo, essas mesmas enfermeiras voltaram a se preocupar com questões da própria profissão, recrutando assim novos profissionais e, também, encaminhando estes mesmos para aprimoramento e reciclagem constante dos seus conhecimentos, com a criação dos cursos de Especialização.

Também é oportuno dizer que, com as dificuldades que as enfermeiras enfrentaram, por um período de suas vivências, começou-se a questionar sobre os currículos das escolas de enfermagem. Depois de muito se discutir, resolveu-se reformula-lo, baseando-se em modelos internacionais, mas se desprendendo dos temas não muito relevantes para a Enfermagem Brasileira, incluindo-se o conteúdo de Administração, e dando maior importância aos princípios e teorias de Administração que pudessem ser aplicados à Enfermagem.

Observou-se que dado início da profissionalização da Enfermagem no Brasil, na sua concepção, vem-se travando uma batalha constante pelos seus ideais e propósitos. Isto se dá através da importância de refletir sempre e cultivar a construção do conhecimento, quer na área da saúde, ou em qualquer outra área, como neste relato que ora se finda, no qual se pode apreciar a evolução da Administração em Enfermagem no Brasil.

9. McGrorey RT. Enfermagem profissional. Rev Bras Enferm 1959;12(3):300-8.

10. Lenington BL, Teixeira G. O papel do serviço de enfermagem na organização hospitalar. Rev Bras Enferm 1955;8(3):189-99.

11. Nogueira MG. O Serviço de Enfermagem na face do administrador. Rev Bras Enferm 1956;9(2):67-77.

12. Schott G. Responsabilidade na seleção de Enfermeiras. Rev Bras Enferm 1958;11(2):114-21.

13. Pinheiro MRS. A inclusão de pedagogia, supervisão e administração no currículo das escolas de enfermagem. Anais de Enfermagem 1952;5(4):319-33.

14. Sanna MC. O Ensino da Arte de Administrar em enfermagem na Escola de Enfermagem Anna Nery no início dos anos 40 - um estudo de caso. [tese] Rio de Janeiro (RJ): Escola de Enfermagem Anna Nery, Universidade Federal do Rio de Janeiro; 2001.

15. Alcântara G. Preparo de Enfermeiras para o campo de Enfermagem em saúde pública, administração de enfermaria e ensino e supervisão na Escola de Enfermagem de Ribeirão Preto. Rev Bras Enferm 1960;13(2):201-29. 